\title{
In-Service Training Management-A Case Study in Vietnam
}

\author{
Anh Nguyen ${ }^{1}$ \\ ${ }^{1}$ Department of Education, Hong Linh Town, Ha Tinh, Vietnam \\ Correspondence: Anh Nguyen, Department of Education, Hong Linh Town, Ha Tinh, Vietnam. E-mail: \\ ngtrianh.hl@gmail.com
}

Received: February 5, 2020

Accepted: June 9, $2020 \quad$ Online Published: September 21, 2020

doi:10.5539/ies.v13n10p1

URL: https://doi.org/10.5539/ies.v13n10p1

\begin{abstract}
In-service training is an integral part of an educational system as teachers always need to update their educational and professional knowledge for a more effective teaching delivery. Ensuring the effectiveness of the in-service training programmes is, however, very challenging. In this article, we introduce the use of the CIPO model, i.e., Context-Input-Process-Output, for in-service training management. We extend the classical CIPO model by integrating into it a quality assurance process. We conduct a case study in Vietnam over a sample of 163 teachers and develop an IT training course to demonstrate how the new model can be used in teacher training management. Finally, we discuss about the lessons learned and recommendations.
\end{abstract}

Keywords: teacher in-service training, continuous professional development, CIPO, management, quality assurance

\section{Introduction}

\subsection{Problem Background}

In-service training is part of the continuous professional development (CPD) for teachers and it plays a crucial role for the success of an educational system. The main purpose of in-service training is to provide opportunities for teachers to update their educational knowledge, professional skills, and to adapt to changes in the curriculum or educational policies. Therefore, teacher training is an important activity for schools around the world and this is especially true for developing countries like Vietnam, where there is a higher need to update the educational system to adapt to societal changes.

Recognising the importance of having in-service training and CPD for teachers, the Vietnamese government has invested significant efforts to run regular training programmes nationwide (Vietnam Ministry of Education, 2012; Vietnam Ministry of Posts and Telecommunications, 2007). The current practice of teacher training in Vietnam, however, still has many drawbacks in terms of its effectiveness in meeting the needs of the teachers and in positively transforming the changes to the delivery to students. Currently, most of the in-service training activities are taken place through a hierarchical process where the national department of education provides guideline or training to representatives at provincial and regional departments of education before the representatives provide training to local teachers. The management of in-service training programmes is, therefore, rather challenging because this is often a coordinated activity between different management levels, from the national to regional departments of education to local schools and between different social stakeholders related to education.

\subsection{Research Aims}

In this work, we propose to develop a systematic model for in-service training management. The management of teacher training activities include managing the development of the training plans and programs, the implementation of the activities, and finally the inspection and evaluation of the outcomes. We show how the CIPO model can be used in teacher training management. In addition, we show how to extend the classical model to include quality assurance. We provide a case study to demonstrate the steps involved in the designing and conducting an IT training program to a sample of teachers in Ha Tinh, a province with a mixture of rural and urban towns in the central of Vietnam. Although the focus of this work is for in-service training in Vietnam, the extended CIPO model and the lessons learned from the case study could be applicable to other countries, especially those with a hierarchical management structure for teacher training. 


\subsection{Relevant Literature}

\subsubsection{In-Service Training for Teachers}

The terms continuous professional development (CPD) is defined to include all activities related to the expanding and updating useful knowledge and skills to enhance a career performance (Lessing \& Witt, 2007). CPD appears in all types of occupations. In education, the needs for in-service training has been analysed in details by Shaw (1995), whereby the importance of teacher training in England has been recognized since 1944. The main purposes for teacher training are both to meet the continuous changes from social needs and to improve the effectiveness of teachers in schools. Dean (1977) and Gaible and Burns (2005) emphasise that, although the subjects of professional development are the teachers, the ultimate beneficiaries are the students and it is important to evaluate how the training programmes affect practice in schools and classrooms.

Gaible and Burns (2005) define teacher CPD as training programs for teachers to improve professional, pedagogical and technical skills. Occasionally, through these programs, radical educational requirements and policies from the higher levels are communicated to the teachers. The authors also emphasize that teacher training is a long-term and continuous process, and hence we have the terms 'in-service training' and 'continuous professional development'. Teacher career development includes not only courses to update knowledge but also other forms such as sharing teaching experiences (Gaible \& Burns, 2005).

The importance of teacher training has been paid much attention in developed countries. In the UK, primary and secondary school teachers each have five days to foster themselves at school. These are called INSET days, where the acronym comes from the initials of the phrase 'in-service training'. According to Bradley, Conner and Southworth (1994), the INSET model of training dates back to 1978. On these days, students do not come to the school so that teachers and the school administration team and other staff can conduct the training programme. According to a survey conducted by Hustler, McNamara, Jarvis, Londra and Campbell [HMJLC] (2003), the main contents of a teacher training programme include planning to develop the curriculum (being allocated about $28 \%$ of the total training period), teaching methods (27\%), professional knowledge $(20 \%)$, and management issues $(17 \%)$. There are also other contents such as helping students, the process of grading and returning exams etc. According to the authors, $71 \%$ of the time of the INSET programme is run by teachers and school administrators while $12 \%$ of these are from local officials. The participants might come from other schools, universities, and companies etc.

\subsubsection{In-Service Training Effectiveness and Management}

Recently, there have been a number of empirical studies on the effectiveness of in-service training programmes around the world. Ozer (2004) studies in-service education in Turkey and concludes that only a small number of teachers who have undertaken the programmes willingly. Ayvaz-Tuncel and Çobanoğlu (2018) conduct a descriptive study over 494 teachers who took the training. The authors make a rather strong conclusion that "in-service training did not make any contribution to some teachers and their personal development" and suggest that "more time and effort should be invested into the planning process". Uztosun (2018) studies feedbacks from teachers in Turkey on the effectiveness of in-service training programmes. The author provides a list of weaknesses emerging from these programmes and concludes that there is a lack of matching between the training contents and the teachers' needs.

Sabri (1997) studies the effectiveness of the in-service teacher training programmes in Palestine and concludes that planning the lesson and setting the objectives are the most important factors for the success of a training programme. Nzarirwehi and Atuhumuze (2019) study in-service training effectiveness in Uganda and conclude that the benefits of the training "can only be realized when the training is properly planned, implemented and continually evaluated, and in the presence of certain resources and incentives." Omar (2014) also highlights the benefits of having in-service education in Malaysia and re-emphasise the importance of meeting the need of teachers. Haydn, Barton and Oliver (2008), in particular, suggests that more focuses should be placed on a bottom up approach where extra teacher-led activities are allocated to the teacher CPD.

Shaw (1995) suggests that in order for in-service training to be effective, there must be a combination between regular trainings at school and training through external organizations. In-service training not only provides teachers with new knowledge and skill sets but also to allow all stakeholders including teachers and management staff to review the effectiveness of the teaching process, and to propose and implement further training. In the case the knowledge need updating and retraining must be acquired from outside, the school will invite outside organizations to guide.

Hustler et al. (2003) argue that the design of the teacher CPD programme should be appropriate to the specific 
needs of the school, the needs of the society and the needs of individual teachers. Gaible and Burns (2005) also suggest that teacher training will get the best effect if it meets the needs of teachers and students. It should be emphasised that the pedagogical skills and knowledge of each teacher is different, and hence it is not effective if all teachers are taking the same training programme. High performing teachers might not be interested in attending the training classes at an elementary level. Therefore, different options for the teachers are needed. In addition, Gaible and Burns (2005) also think that the training programme needs to focus on the students' output criteria and needs to consider the student as the centre.

\subsubsection{The General CIPO Model}

The CIPO model was introduced by Scheerens $(1990,1995)$ with the original purpose to create a model to evaluate the effectiveness of school activities or an educational system. The elements of the CIPO model are divided into four basic groups as shown in Figure 1.

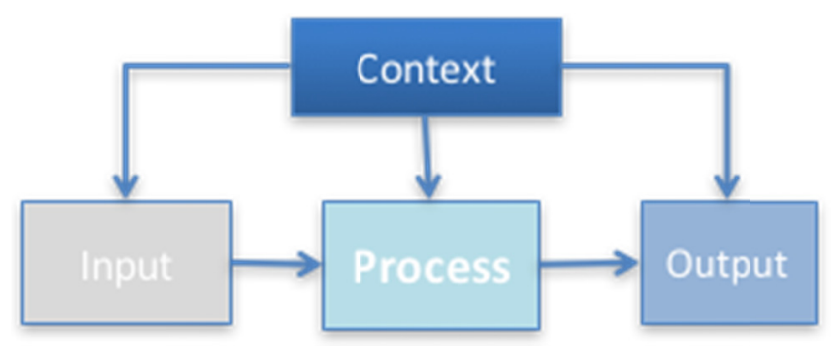

Figure 1. A general CIPO model

Here, CIPO is the abbreviation of Context (C), Input (I), Process (P) and Output/Outcome (O), which are the four basic groups with the following contents:

- Context: including all factors that affect the educational system such as educational policies, technological changes, or societal needs.

- Input: Including the infrastructure, the financial conditions of the schools, the demand and the current knowledge level of the teachers.

- Process: Including all the methodology, implementation and activities involved in achieving the objectives.

- Output/Outcome: Including the analyses of the outputs with respect to the input and the standard set out in the context to evaluate the effectiveness of the programme.

Since introduced, the CIPO model is regarded as a suitable framework for educational management. The model is based on the common ground of dividing a complex system into stages: context, input, process and output. Moelands and Ouborg (1998), ODEAD (2011), and Zhang, Yang, Chang, and Chang (2016) use the CIPO model for school evaluation in Netherlands, Belgium and China, respectively. Chang and Lin (2018) use the C-I-P-O stages as dimensions of internationalisation to develop a set of indicators for examining the higher education in Taiwan. In addition to the evaluation of traditional performance measures, the CIPO model has been used for measuring the school effectiveness in terms of the students' wellbeing (Petegem, Aelterman, Keer, \& Yves, 2007) and for evaluation of character and moral education at elementary schools (Meivawati, Kartowagiran, \& Rustini, 2018).

Although the traditional CIPO model, as shown in Figure 1, includes the Output stage, it does not provide a detailed framework for evaluating the effectiveness of the training process. In this article, we introduce an extended CIPO model with a combination of a quality assessment process in teacher training management as will be described in the next section.

\section{Method: Extended CIPO Model for In-Service Training}

In-service training activities take place according to a process, from the inputs to outputs, along with the influence of the context affecting the elements of the training process. Therefore, it is appropriate to use the CIPO model to manage the teacher training process. It is important that managers see the characteristics of these C - I - P - O factors in order to effectively manage the in-service training activities. Here, the Context includes educational policies, guidelines, as well as goals related to improving the quality of education. The Input here is related to the 
needs of teachers, their professional competency and the current situation involving their training. The Process includes analysing and evaluating training needs of teachers, developing training contents and platform as well as how to manage the system. Finally, the Output includes the relative comparison of the quality of the teacher between before and after the training process.

Recognising the importance of having a thorough quality assurance process as well as acknowledging the difficulties in the hierarchical management of in-service training in Vietnam, we extend the traditional CIPO model for in-service training as is summarized in Figure 2.

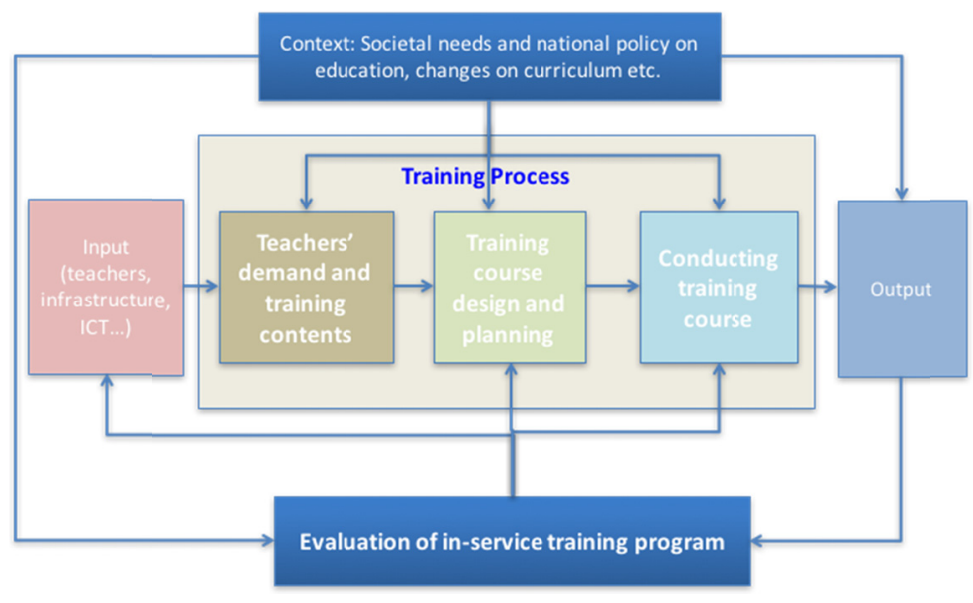

Figure 2a. Extended CIPO model for in-service training management

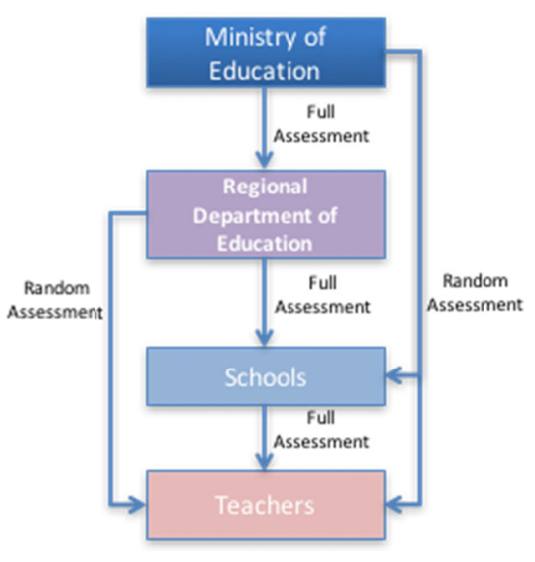

Figure 2b. Quality assurance model

In Figure 2a, we provide a detailed description of the stages involved in in-service training. A critical difference between the extended CIPO model compared to the traditional model is the incorporation of the evaluation stage, which forms a feedback loop from the output to the training process. Here, we emphasise the fact that the evaluation of the outcome should not be waited until the final output stage. Instead, we suggest providing assessment and feedback, which could be of formative or summative assessment forms (Biggs \& Tang, 2007).

Finally, in Figure 2b, we suggest a framework for assessment when the in-service training program involves multiple layers of management. It is of the ministry of education's interest to know the effectiveness of the training process at regional, school and individual teacher levels. The reason behind this is due to a rather unfortunate fact that, due to competition, some schools or regional departments of education have the tendency to over-claim the effort and effectiveness that they put into the training programmes. It is noted, however, that, while recognising the importance of evaluation, it is costly for the ministry of education to perform full assessment (and the following-up actions) to the school level, let alone with the individual teacher level. We propose to incorporate a mixture of full and random assessments where the latter is used for cases with no direct management links, i.e. from the ministry of education or the regional department of education to teachers. The cross-assessment enforces all the middle management levels and individual teachers to pay adequate effort in conducting the training programme and to improve its effectiveness. In the next section, we will describe a case study of an IT course in Vietnam to demonstrate how the extended CIPO model can be used in teacher training management.

\section{Experimental Design and Results: Case Study of Running a Mini IT Course in Vietnam}

In order to demonstrate the use of the extended CIPO model in teacher training, we conduct a mini IT course for 163 teachers in Hong Linh town, Ha Tinh province, which is in the central of Vietnam. The teachers come from six secondary schools in Ha Tinh and include 53 males and 110 females. The six secondary schools represent a typical sample of teachers in Vietnam in terms of the schools' performance compared to others in Ha Tinh and in Vietnam.

We focus on developing a specific IT course and presenting the key steps in applying the CIPO model to this course. In section 4.2, we explain how the training course was chosen and designed (i.e., Context \& Input). We then describe how the course is conducted as well as the evaluation of the results in Section 4.2 (i.e., Process, Output and Evaluation). Finally, we discuss the lessons learned in Section 4. 


\subsection{Finding the Demands and Contents of CPD Programs (Context \& Input)}

In terms of Context, there have been many documents confirming the goals and policies of the Vietnam National Department for Education on the need to improve the quality of teacher in-service training and to apply ICT in teaching (Vietnam Ministry of Education, 2012; Vietnam Ministry of Posts and Telecommunications, 2007). In order to find out the most essential contents for the in-service training programme, we conduct a survey over the sample of all the teachers from six secondary schools in Ha Tinh (163 teachers in total). The teachers are asked to choose the most relevant training programme that they need; these include A) professional training on subjects such as Math, Physics ..., B) Training on occupational ethics, C) Training on teaching methodology, and D) Training on information technology. The survey results show that IT is the topic that the teachers need the most.

We then interview a random sample of teachers to understand the barrier for them concerning IT skills. It is quite surprise that many teachers are hesitant in using computers for preparing electronic teaching materials in Words or PowerPoint mainly because of their slow typing skills. Many believe that they are not using the right fingering techniques. The time taken to prepare lecture materials varies significantly from one teacher to another. On average, to prepare for a 45 -minute lecture, some teachers take about 20 minutes, while some other takes more than 2 hours. Although this partly depends on the subject experience and the knowledge of the teacher, the main underlying reason for this is due to the variation on the IT skills and largely on the typing speed. In fact, older generation teachers often has a greater educational experience but still spend longer time preparing for teaching materials due to their inferior IT skills in general and typing in particular.

\subsection{Designing and Conducting the Training Program and Evaluation of Outcome (Process \& Output)}

The survey and interviews led us to designing a mini typing course for the teachers and for us to put the remaining parts of the CIPO model into practice. The program selected is from https://www.typingstudy.com/en-vietnamese-3/, which has been used free-of-charge by people around the world. The course is available in over 100 combinations of keyboard settings and languages including Vietnamese. The program includes 15 lessons to practice typing skills. Each lesson includes online exercises and these are formative assessments. There is also a final exam of the course.

The mini IT course is taken by all the teachers, who are introduced to the typing course by the educational department and the schools' administration teams. Each teacher registers an account and participates in online theory and practice lessons. After each lesson, the teacher sends the practice results to the school administration and the educational department. The result will show the speed and accuracy of the teacher in using the characters on the keyboard. From there, the administrators and the education department can give specific formative feedbacks (for example, the aspects that teachers should practice more). The mini course includes a final test on the teachers' IT skill. The online test provides us with individual teacher's scores.

As teachers are taking the training courses in the same way as students are learning, we pay particular attention to the feedback mechanism, which can be classified into the two most important categories: formative and summative feedback (Biggs \& Tang, 2007). The online exercises are viewed as formative assessments and teachers received constant feedback on their progress. The final test and results are considered as summative feedback. Black and William (1998) argue that there is strong evidence that improving formative assessment raises standards of achievements.

We also provide post-evaluation of the teachers' typing skills through surveys and interview. In addition to the typing skills, teachers report that the course provide them with more confidence to use computer for their educational purpose such as preparing for lecture notes or slides.

\section{Discussion: Lessons learned and Recommendations}

The first lesson that we have learned is on the importance of incorporating the teacher's need in designing in-service training programme. This reaffirms the finding from the literature including Sabri (1997), Nzarirwehi and Atuhumuze (2019), Omar (2014), Bozkurt et al. (2012) and Haydn, Barton, and Oliver (2008). We also find that conducting surveys and interviews can provide us with helpful information. For example, from the interview, we learn that many teachers expressed their barrier to using computer for preparing electronic teaching material because of their lack of confidence in typing despite the fact that most of them have received basic IT training certificates from universities or third parties in the past. This is due to an interesting fact that the importance of the typing skills was undermined in those past IT training programmes.

Second, we find that output management is important for in-service training activities because it is not only for the pure evaluation of the training results but also to monitor and evaluate the performance of each teacher and their career advancement. This also allows us to assess the quality and effectiveness of the training programmes and to 
adjust the training process accordingly to meet teachers' needs and societal changes. In order to effectively manage the outputs, it is necessary for teachers to register the plan of applying the training results into practice. In our case, we ask teachers to apply what they learned (i.e., typing skills) into their daily work (i.e., preparing lecture materials).

Third, we re-emphasise the importance of incorporating the evaluation process into the training program. We also find that random assessment can be helpful where multiple level of management is involved in the process. The evaluation of in-service teaching activities involves assessing individual outcomes as well as comparing between the training results against the objectives and the criteria set out in the programme. Through inspection and evaluation, a reverse information channel can be created so that the management team can receive feedback to adjust the training programme as well as the training process to achieve further efficiency in the future.

\section{Conclusion}

In this paper, we introduce an extended CIPO model for managing the in-service training process for teachers. We demonstrate the model by designing a small IT training course and by describing the steps involved, from studying the context to understanding the real needs of the teachers to actually conducting the course. The extended CIPO model also incorporates the quality assurance during the process so that constant feedback and adjustments could be made. In the case there are multiple levels of management involved, random assessment can help enable cross-evaluation while reducing the cost. Finally, we conduct a mini IT training course in Vietnam over 163 teachers from six secondary schools in order to demonstrate the steps involved in the extended CIPO model. Lessons from running the course re-emphasise the crucial role to study the needs of the teachers while designing the training program and the importance of incorporating the quality assurance into in-service education. In the context of this article, we demonstrate use of the extended CIPO model in managing a mini IT training course for teachers; the framework and the lessons, however, can be applied to other in-service training contexts or general continuous professional development courses.

\section{Acknowledgements}

We would like to thank the participants of the in-service training course conducted at six secondary schools in Hong Linh Town, Ha Tinh, Vietnam.

\section{References}

Abbott, C. (2001). ICT: Changing Education. Routledge, London and New York. https://doi.org/10.4324/9780203400197

Ager, R. (2003). Information and Communications Technology in Primary Schools: Children or Computers in Control? David Fulton Publishers, London. https://doi.org/10.4324/9780203824320

Ayvaz-Tuncel, Z., \& Çobanoğlu, F. (2018). In-service Teacher Training: Problems of the Teachers as Learners. International Journal of Instruction, 11(4), 159-174. https://doi.org/10.12973/iji.2018.11411a

Biggs, J., \& Tang, C. (2007). Teaching for Quality Learning at University (3rd ed.). Maidenhead: McGraw-Hill Education.

Black, P., \& William, D. (2010). Inside the Black Box: Raising Standards Through Classroom Assessment. Phi Delta Kappa, 92(1), 81-90. https://doi.org/10.1177/003172171009200119

Bozkurt, E., Kavak, N., Yamak, H., Bilici, S. C., Darici, O., \& Ozikaya, Y. (2012). Secondary school teachers' opinions about in-service teacher training: A focus group interview study. Social and Behavioral Sciences, 46, 3502-3506. https://doi.org/10.1016/j.sbspro.2012.06.093

Bradley, H., Conner, C., \& Southworth, G. (1995). Developing Teachers Developing Schools: Making INSET Effective for the School. David Fulton Publishers, London. https://doi.org/10.2307/3121998

Chang, D. F., \& Lin, N. J. (2018). Applying CIPO indicators to examine internationalization in higher education institutions in Taiwan. International Journal of Educational Development, 63, 20-28. https://doi.org/10.1016/j.ijedudev.2017.12.007

Dean, J. (1977). Making In-Service Education Effective. Journal of In-Service Education, 4(1-2), 41-44. https://doi.org/10.1080/0305763770040107.

Gaible, E., \& Burns, M. (2005). Using Technology to Train Teachers: Appropriate Uses of ICT for Teacher Professional Development in Developing Countries. ICT AND EDUCATION SERIES, The World Bank.

Hall, D. (2010). The ICT Handbook for Primary Teachers: A Guide for Students and Professionals. Routledge, London and New York. https://doi.org/10.4324/9780203862933 
Haydn, T., Barton, R., \& Oliver, A. (2008). An alternative model of continuing professional development for teachers: Giving teachers time. International Education Studies, 1(1), 44-49. https://doi.org/10.5539/ies.v1n1p44

Hustler, D., McNamara, O., Jarvis, J., Londra, M., \& Campbell, A. (2003). Teachers perceptions of continuing professional development. Research Report No 429. Manchester Metropolitan University.

Lessing, A., \& Witt, M. (2007). The value of continuous professional development: Teachers' perceptions. South African Journal of Education, 27(1), 53-67.

Meivawati, E., Kartowagiran, B., \& Rustini, T. (2018). Evaluation of character and moral education in elementary. The Online Journal of New Horizons in Education, 8(4), 63-72. Retrieved from https://www.tojned.net/journals/tojned/volumes/tojned-volume08-i04.pdf\#page=70

Moelands, H. A., \& Ouborg, M. J. (1998). School Self Evaluation in Primary Education in the Netherlands. Paper presented at the European Conference on Educational Research (ECER98), Ljubljana, Slovenia.

Nzarirwehi, J., \& Atuhumuze, F. (2019). In-service teacher training and professional development of primary school teachers in Uganda. IAFOR Journal of Education, 7(1). https://doi.org/10.22492/ije.7.1.02

OECD. (2011). School Evaluation in the Flemish Community of Belgium 2011. OECD Reviews of Evaluation and Assessment in Education, OECD Publishing.

Omar, C. M. Z. C. (2014). The Need for In-Service Training for Teachers and its Effectiveness in School. Int. J. Innov. Educ. Res., 2, 1-9.

Ozer, B. (2004). In-service training of teachers in Turkey at the beginning of the 2000s. Journal of In-Service Education, 30(1), 89-100. https://doi.org/10.1080/13674580400200301

Peck, C., McCall, M., McLaren, B., \& Rotem, T. (2000). Continuing medical education and continuing professional development: International comparisons. https://doi.org/10.1136/bmj.320.7232.432

Perraton, H. (1999). Distance education for teacher training. Routledge, London and New York. https://doi.org/10.4324/9780203304075

Petegem, K. V., Aelterman A., Keer, H. V., \& Yves, R. (2007). The influence of student characteristics and interpersonal teacher behaviour in the classroom on student's wellbeing. Social Indicators Research, 85, 279-291. https://doi.org/10.1007/s11205-007-9093-7

Sabri, K. S. (1997). In-service teacher training programmes: The case of Palestine. British Journal of In-Service Education, 23(1), 113-118. https://doi.org/10.1080/13674589700200006

Scheerens, J. (1990). School effectiveness research and the development of process indicators for school functioning. School Effectiveness and School Improvement, 1(1), 61-80. https://doi.org/10.1080/0924345900010106

Scheerens, J. (1995). School effectiveness as a research discipline. Paper presented at the International Congress of School Effectiveness and School Improvement, The Netherlands, Leeuwarden.

Shaw, R. (1995). Teacher Training in Secondary Schools. Kogan Page Limited, London.

Uztosun, M. S. (2018). In-Service Teacher Education in Turkey: English Language Teachers' Perspectives. Professional Development in Education, 44(4), 557-569. https://doi.org/10.1080/19415257.2017.1374989

Vietnam Ministry of Education. (2012). Circular 26/2012/TT-BGDĐT, Promulgation of regulation on continuous professional development for primary, secondary and high school teachers.

Vietnam Ministry of Posts and Telecommunications. (2007). Directive 07/CT-BBCVT, ICT Development Strategy for Vietnam between 2011-2020.

Zhang, J., Yang, J., Chang, M., \& Chang, T. (Eds.). (2016). ICT in education in global context: The best practices in K-12 schools. Singapore: Springer. https://doi.org/10.1007/978-981-10-0373-8

\section{Copyrights}

Copyright for this article is retained by the author(s), with first publication rights granted to the journal.

This is an open-access article distributed under the terms and conditions of the Creative Commons Attribution license (http://creativecommons.org/licenses/by/4.0/). 